\title{
COMPORTAMENTOS DE RISCO NO TRÂNSITO ENTRE ESTUDANTES UNIVERSITÁRIOS EM PONTA GROSSA-PR, 2005
}

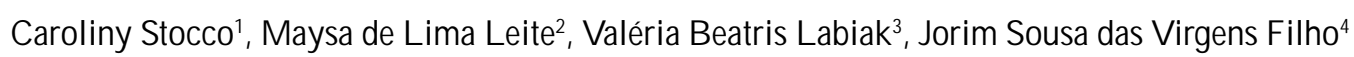

RESUMO: A alta incidência de acidentes de trânsito (AT's) envolvendo jovens tem sido atribuída aos comportamentos próprios da idade. A ssim, o presente estudo teve como objetivo associar comportamentos de risco no trânsito a características demográficas e ao envolvimento em AT's entre estudantes universitários de cursos na área da Saúde da Universidade Estadual de Ponta Grossa - PR, em 2005. Utilizou-se um questionário auto-respondido, cujas variáveis estudadas foram: características demográficas, comportamentos de risco no trânsito e envolvimento em AT's como motorista. A amostra total compreendeu 624 acadêmicos, tendo sido excluídos 126 que não dirigiam. A plicaram-se os testes de associação do qui-quadrado e odds ratio, com nível de significância de $5 \%$. Para os comportamentos de risco em estudo, o sexo masculino e a faixa etária entre 20 a 21 anos apresentaram maior freqüência para tais comportamentos. A associação entre os comportamentos de risco e o envolvimento em acidentes revelou dependência entre as variáveis. DESCRITORES: A cidentes de Trânsito; Comportamentos; Estudantes; Epidemiologia.

\section{RISK BEHAVIORS IN THE TRAFFIC AMONG ACADEMIC STUDENT IN PONTA GROSSA-PR, 2005}

\begin{abstract}
The high incidence of traffic accidents (TA s) involving young people has been attributed to proper behaviors at their age. Thus, the present study objectified to associate risk behaviors in the traffic to demographic characteristics and the involvement in TA s among academic students of the Health area at Ponta G rossa State U niversity - Paraná State in 2005. A self-answerable questionnaire was used, whose studied variables were: demographic characteristics, risk behaviors in the traffic and involvement in TA s as drivers. The total sample took up 624 academics, having been excluded 126 that didn't drive. A ssociation tests of the chi-square and odds ratio were applied, with significant level of $5 \%$. For the studied risk behaviors, males and the age group ranging 20 to 21 years presented a larger frequency of such behaviors. The association between the risk behaviors and the involvement in accidents reveal ed dependence among the variables.
\end{abstract}

DESCRIPTORS: Traffic accidents; B ehavior; Students; Epidemiology.

\section{LAS CONDUCTAS DE RIESGO EN EL TRÁNSITO ENTRE LOS ESTUDIANTES UNIVERSITARIO EN PONTA GROSSA-PR, 2005}

RESUMEN: La al ta incidencia de accidentes de tránsito (ATs) envolviendo los jóvenes viene siendo atribuida a las propias conductas de la edad. A sí, el estudio presente tuvo como objetivo asociar riesgo de conductas en el tráfico a las características demográficas y el envolvimiento en ATs entre los estudiantes universitarios de cursos en el área de la Salud de la U niversidad Estadual de Ponta G rossa - PR, en 2005. Fue utilizado un cuestionario ya autocontestado, cuyas variables estudiadas fueran: Ias características demográficas, conductas de riesgo en el tránsito y envolvimiento en ATs como conductores. La muestra total comprendió 624 académicos, siendo excluidos 126 que no conducían. Fueran aplicadas las pruebas de asociación del "qui-cuadrado" y proporción de desigual dades, con el nivel significante de 5\%. Para las conductas de riesgo en estudio, el sexo masculino y la franja etaria entre 20 y 21 años presentaron mayor frecuencia. La asociación entre las conductas de riesgo y el envolvimiento en los accidentes reveló la dependencia entre las variables.

DESCRIPTORES: Accidentes de tráfico; Conducta; Estudiantes; Epidemiología.

\footnotetext{
${ }^{1}$ B acharelado em Enfermagem, Universidade Estadual de Ponta Grossa -UEPG.

2 Departamento de Biologia Geral da UEPG.

${ }^{3}$ Bacharelado em Enfermagem da UEPG.

${ }^{4}$ Departamento Informática da UEPG.
}

Av. Carlos Cavalcanti, 4748 - 84030-900 - Ponta Grossa-PR Recebido em: 28/11/06

E-mail: maysaleite@globo.com 


\section{INTRODUÇÃO}

Os jovens, principalmente do sexo masculino, são as vítimas mais freqüentes nos acidentes de trânsito(1,2). No Paraná, em 2004, o coeficiente de mortal idade por acidentes de trânsito, na população em geral, foi de 32,16 óbitos por 100.000 habitantes ${ }^{(3)}$. Em Ponta Grossa, esse coeficiente de mortalidade foi superior ao do Estado perfazendo 32,32 óbitos por 100.000 habitantes $^{(3)}$.

Essa alta incidência de acidentes envolvendo a população jovem tem sido atribuída aos comportamentos próprios da idade como impulsividade, confiança excessiva, ousadia, "busca por sensações fortes" e necessidade de afirmação perante o grupo de amigos. Devido a essas características de personalidade, os jovens tendem a transgredir as leis de trânsito, como desrespeitar limites de velocidade, fazer ultrapassagens proibidas, ingerir bebidas al coólicas prévias à direção, entre outros ${ }^{(4-7)}$. A lém disso, outras características como envolvimento anterior em acidentes de trânsito, reações emocionais e opiniões sobre a conduta referidas pelo próprio motorista também poderiam ser um prognóstico para a ocorrência de um acidente.

Estudos nacionais e internacionais têm sido realizados sobre comportamentos de saúde entre adolescentes e jovens ${ }^{(8-11)}$, por entender que mudanças nestes comportamentos poderiam refletir de forma positiva na saúde deste segmento da população. No B rasil, os estudos sobre comportamentos de risco para acidentes de trânsito entre jovens vêm crescendo gradativamente $^{(2,6,12)}$. No entanto, a grande maioria baseia-se num contexto geral de prevalência, sendo necessário ampliar estudos de sobreposição entre esses comportamentos eassociação destes com características demográficas, sócio-econômicas e emocionais.

$\mathrm{N}$ esse contexto, os comportamentos têm merecida importância na contribuição de acidentes de trânsito, tornando-se o foco principal de alguns estudos $^{(12)}$. A ssim, o presente trabalho apresenta um inquérito epidemiológico sobre comportamentos de risco no trânsito associados a características demográficas, sexo eidade, e ao envolvimento anterior em acidentes de trânsito, na condição de motorista, entre estudantes universitários de cursos na área da Saúde.

\section{MÉTODOS}

0 presente estudo tem caráter epidemiológico de corte tranversal, descritivo e quantitativo. A pesquisa foi realizada no ano de 2005 com estudantes universitários de cursos na área da Saúde, Ciências B iológicas, Educação Física, Enfermagem, Farmácia e Odontologia, da Universidade Estadual de Ponta Grossa - UEPG. A amostra foi composta por alunos matriculados nestes cursos, distribuídos do 10 ao 4 으 ano, Ciências Biológicas, Educação Física, Enfermagem, Farmácia, e do 1ำao 50 ano 0 dontologia.

0 instrumento utilizado para a coleta de dados foi um questionário auto-respondido, de maneira anônima, elaborado com base na pesquisa "Y outh Risk B ehavior Survey", desenvolvida nos Estados U nidos da A mérica, a qual monitora anualmente comportamentos de saúde de jovens norte-americanos ${ }^{(11)}$.

As acadêmicas de Enfermagem envolvidas no presente estudo foram treinadas previamente para a aplicação, col eta e transcrição dos dados da pesquisa. Os questionários foram aplicados durante as atividades acadêmicas, no início da aula, e com consentimento prévio dos estudantes, mediante assinatura de Termo de Consentimento Livre e E sclarecido, tendo esses a liberdade em recusar a participação. A ntes do preenchimento do questionário foi informado aos alunos o objetivo da pesquisa, reforçando 0 anonimato, com a finalidade de conseguir maior confiabilidade das informações obtidas. Cada aplicação de questionário nas salas de aula teve duração média de 20 a 30 minutos.

As variáveis estudadas foram: Características demográficas: sexo e idade. Comportamentos de risco no trânsito: "nem sempre respeitar o limite de velocidade", "nem sempre respeitar o semáforo", "fazer conversões ilegais", "fazer ultrapassagem proibida", "falar ao celular quando dirige", "dirigir após ingestão de bebida alcoólica nos últimos 30 dias", "uso de drogas", "participação em rachas", "participação em brigas e discussões de trânsito". Envolvimento anterior em acidentes de trânsito como motorista.

Os dados obtidos foram inseridos na planilha Excel para a criação do banco de dados e cálculo das freqüências. Posteriormente, algumas variáveis foram analisadas com o emprego do programa Bioestat 2.0, onde foram aplicados os testes de associação do quiquadrado e odds ratio, com nível de significância de $5 \%$.

A pesquisa foi aprovada pelo Comitê de Ética em Pesquisa com Seres Humanos da UEPG, e os dados obtidos foram utilizados para fins exclusivos de pesquisa científica preservando a identidade dos 
sujeitos, de acordo com a Resolução n. 196/96 do Conselho Nacional de Saúde.

\section{RESULTADOS E DISCUSSÃO}

A amostra total compreendeu 624 acadêmicos, tendo sido excluídos 126 que não dirigiam, perfazendo 196 do sexo masculino e 302 do feminino. Vale ressaltar que houve questionários onde algumas questões não foram respondidas, tendo sido considerados apenas os estudantes que responderam todas as questões referentes aos comportamentos em estudo. A ssim, a amostra final para verificar associação entre características sóciodemográficas e comportamentos de risco no trânsito compreendeu 467 acadêmicos, sendo 187 do sexo masculino e 280 do feminino. Já a amostra final para verificar associação entre antecedentes em acidentes de trânsito e comportamentos de risco no trânsito foi composta por 290 acadêmicos, onde 115 tiveram envolvimento anterior em acidentes como motorista e 175 não tiveram envolvimento anterior.

No B rasil, em 2002, os condutores do sexo masculino foram os mais envolvidos em acidentes de trânsito com vítimas, perfazendo $86,94 \%{ }^{(13)}$. Houve também predominância do sexo masculino entre as vítimas fatais de acidentes de trânsito, perfazendo $79,81 \%^{(14)}$. No município de Ponta Grossa-PR, entre 2002 e 2004, os condutores do sexo masculino foram os que mais envolveram-se em acidentes de trânsito com vítimas, num total de $86,13 \%, 79,67 \%$ e $80,49 \%$ respectivamente, em cada ano. Dentre as vítimas, o sexo masculino também foi o mais acometido nos três anos estudados, correspondendo a 73,94\%, 71,39\%, $73,01 \%$, respectivamente ${ }^{(15)}$.

Os resultados apresentados na Tabela 1 demonstram que, quanto ao respeito do limite de velocidade segundo o sexo, 58,82\% dos rapazes relataram que nem sempre respeitam o limite, enquanto que no universo feminino encontrou-se freqüência de 38,93\%, havendo então diferença estatística altamente significativa $(p=0,0000)$. Diferentemente do presente estudo, outra pesquisa realizada em $L$ ondrina-PR não encontrou valor estatístico significativo, no entanto foi observada al ta freqüência, em ambos os sexos, para a prática deste comportamento de risco tendo sido relatado por $83,50 \%$ dos rapazes e $82,8 \%$ das jovens ${ }^{(6)}$. Em estudo realizado no Reino U nido, observou-se que
$83,0 \%$ dos homens não respeitam o limite de velocidade, e uma freqüência muito superior entre as mulheres perfazendo $97,7 \%{ }^{(4)}$. Outros estudos discutem que a velocidade que 0 carro pode atingir constitui a oportunidade ao motorista de sentir grandeza, onipotência e independência ${ }^{(16)}$, e que 0 excesso de velocidade estaria associado ao descaso e a agressividade ${ }^{(17)}$.

Com relação ao respeito ao semáforo, $26,74 \%$ dos rapazes e $18,93 \%$ das jovens declararam transgressão. Neste caso, não foi observado valor estatístico significativo $(p=0,0600)$ entre os sexos, revelando independência entre as variáveis analisadas. Diferentemente do presente estudo, outra pesquisa encontrou diferença estatística significativa entre os sexos $(p=0,0400)$, tendo sido encontrada freqüência superior, em ambos os sexos, para 0 desrespeito perfazendo $53,50 \%$ no sexo masculino e $36,20 \%$ no sexo feminino ${ }^{(6)}$. Conforme sugerido em outro estudo, os homens seriam prédispostos às transgressões por cometerem erros em maior freqüência que as mulheres ${ }^{(18)}$.

$M$ ais da metade dos rapazes relatou fazer conversões ilegais $(58,29 \%)$ e entre as jovens encontrou-se relato de $32,50 \%$ para a prática deste comportamento indesejável no trânsito, tendo sido observado valor estatístico al tamente significativo $(p=0,0000)$. Também encontrou-se val or estatístico altamente significativo para a prática de ultrapassagens proibidas $(p=0,0000)$ e alta freqüência para este comportamento no sexo masculino (44,92\%). Já no sexo feminino, apenas $21,07 \%$ das jovens relataram este tipo de comportamento. Esses dados corroboram com estudo(6) que analisou comportamentos de risco entre estudantes que dirigem regularmente automóveis, onde foi encontrada diferença estatística significativa entre os sexos para os dois últimos comportamentos analisados anteriormente, "fazer conversões ilegais" e "fazer ultrapassagem proibida".

Embora o comportamento falar ao celular enquanto dirige não tenha apresentado significância estatística $(p=0,0961)$, encontrou-se al ta freqüência, em ambos os sexos, perfazendo $52,94 \%$ no sexo masculino e $44,64 \%$ no grupo feminino. A independência entre as variáveis revela que este comportamento indesejável é estatisticamente semel hante em ambos os sexos. Em outro estudo(6), também não foi encontrada diferença estatística 
significativa, no entanto foi observada alta freqüência, em ambos os sexos, perfazendo $41,60 \%$ no sexo masculino e $48,90 \%$ no sexo feminino.

Q uanto ao relato de ingerir bebidas al coólicas prévia à direção, encontrou-se valor estatístico al tamente significativo $(p=0,0000)$, onde $43,85 \%$ dos rapazes declararam ingestão prévia e entre as jovens encontrou-se uma freqüência de 19,29\%. Outro estudo(19) que realizou associação entre características demográficas e sócio-econômicas e a ingestão de bebidas alcoólicas prévia à direção discutiu que $16,49 \%$ dos homens relataram ter ingerido bebidas alcoólicas 4 vezes ou mais antes de dirigir nos últimos 30 dias, contra apenas 3,34\% de relatos no sexo feminino. Com relação à renda mensal dos pais, a renda entre 10 e 18 salários mínimos foi a que apresentou maior relato para ingestão onde $32,06 \%$ dos estudantes declararam ter utilizado bebidas alcoólicas antes de dirigir.

A utilização de drogas lícitas e ilícitas também apresentou alta freqüência relativa para ambos os sexos, perfazendo $54,01 \%$ no sexo masculino e $38,93 \%$ no sexo feminino $(p=0,0018)$. As drogas citadas como mais utilizadas pelos estudantes foram bebidas alcoólicas, tabaco e maconha, respectivamente. Outro estudo encontrou valor inferior para uso de drogas ilícitas tendo sido encontrado prevalência de $38,10 \%$ entre estudantes universitários da área de Ciências Biológicas ${ }^{(20)}$. Um estudo discutiu que a curiosidade para vivenciar novas experiências aparece como o principal motivo apontado para utilização de $\operatorname{drogas}^{(21)}$.

A participação em "rachas" também apresentou no sexo masculino freqüência relativa significativa $(32,09 \%)$, porém baixa freqüência no sexo feminino $(9,29 \%)$, revelando valor al tamente significativo $(p=0,0000)$. Diferentemente do presente estudo, outra literatura não encontrou diferença estatística significativa entre os sexos, no entanto, encontrou $15,16 \%$ de declaração de participação entre o sexo masculino, o que foi considerado para este estudo como muito significativo, já que esta é uma prática muito perigosa e que coloca em risco tanto os que a real izam, seja como condutor ou passageiro, como para os espectadores ${ }^{(6)}$. Com o objetivo de associar características demográficas e sócio-econômicas de estudantes universitários, outro estudo ${ }^{(22)}$ encontrou associação entre a participação em "rachas" e renda mensal dos pais $(p=0,0000)$, onde $53,26 \%$ dos estudantes com renda entre 10 e 18 salários mínimos declararam a prática deste comportamento.

0 relato para participação em brigas e discussões de trânsito foi de $21,39 \%$ no sexo masculino, enquanto no sexo feminino foi encontrado valor inferior $(8,93 \%)$, revelando associação entre as variáveis $(p=0,0002)$.

Tabela 1 - Freqüências (absolutas (fi) e relativas (fr)) dos comportamentos de risco no trânsito de condutores, segundo sexo entre estudantes universitários de cursos na área da Saúde. Ponta G rossa, 2005

\begin{tabular}{lccccc}
\hline \multicolumn{1}{c}{ Comportamentos de risco no trânsito de estudantes condutores segundo sexo } \\
Comportamentos de risco & \multicolumn{2}{c}{$\begin{array}{c}\text { Masculino } \\
(\mathrm{n}=187)\end{array}$} & \multicolumn{2}{c}{$\begin{array}{l}\text { Feminino } \\
(\mathrm{n}=280)\end{array}$} \\
& $\mathrm{fi}$ & $\mathrm{fr}$ & $\mathrm{fi}$ & $\mathrm{fr}$ & $\mathrm{p}$-value \\
\hline Nem sempre respeita o limite de velocidade & 110 & 58,82 & 109 & 38,93 & 0,0000 \\
Nem sempre respeita o semáforo & 50 & 26,74 & 53 & 18,93 & 0,0600 \\
Faz conversões ilegais & 109 & 58,29 & 91 & 32,50 & 0,0000 \\
Faz ultrapassagem proibida & 84 & 44,92 & 59 & 21,07 & 0,0000 \\
Fala ao celular enquanto dirige & 99 & 52,94 & 125 & 44,64 & 0,0961 \\
Ingestão de bebidas alcoólicas antes de dirigir & 82 & 43,85 & 54 & 19,29 & 0,0000 \\
Uso de drogas & 101 & 54,01 & 109 & 38,93 & 0,0018 \\
Participação em "rachas" & 60 & 32,09 & 26 & 9,29 & 0,0000 \\
Participação de brigas e discussões de trânsito & 40 & 21,39 & 25 & 8,93 & 0,0002 \\
\hline
\end{tabular}

A prática de comportamentos de risco teria uma explicação biológica, segundo estudo de teorias de personalidade, estando relacionados a al tos níveis de testosterona e níveis mais baixos de monoamina- 
oxidase (M A O). 0 indivíduo do sexo masculino sob a ação da testosterona torna-se mais agressivo e lutador desenvolvendo, em geral, os chamados instintos masculinos ${ }^{(23)}$. A ssim, níveis mais baixos de MAO potencializam a ação estimulante da testosterona ${ }^{(24)}$. Essa base biológica resultaria numa característica de personalidade associada à "busca por sensações fortes" ${ }^{\prime \prime}$.

Segundo enfoque da psicologia, o comportamento é resultante do processamento de fatores externos, relativos ao meio ambiente, que serão reinterpretados a partir de referenciais internos que 0 próprio indivíduo constrói e que contribuem para a organização das percepções frente aos riscos e que orientarão o comportamento de prevenção de acidentes $^{(25)}$.

No B rasil, em 2002, a faixa etária mais acometida para os condutores envolvidos em acidentes de trânsito com vítimas foi entre 30 e 59 anos, seguida pela faixa entre 18 e 29 anos, perfazendo $35,24 \%$ e $29,87 \%$, respectivamente. No Paraná, em 2002, a faixa etária mais acometida para condutores também foi entre 30 e 59 anos, seguida pela faixa entre 18 e 29 anos (48,10\% e $36,44 \%$, respectivamente) ${ }^{(13)}$. No município de Ponta Grossa - PR, em 2002, a faixa entre 30 e 59 anos, seguida pela faixa entre 18 e 29 também foram as mais acometidas tendo sido encontradas freqüências el evadas (53,71\% e 39,31\%, respectivamente) $)^{(15)}$.

Os resultados relativos aos comportamentos de risco no trânsito de estudantes condutores classificados conforme as faixas etárias podem ser observados na Tabela 2.

Com relação ao comportamento "nem sempre respeitar o limite de velocidade" segundo a faixa etária, a que apresentou maior freqüência foi a faixa entre 20 a 21 anos perfazendo 36,99\% de relatos, seguida pelas faixas de estudantes com 19 anos ou menos $(25,57 \%)$ e 22 a 23 anos $(25,11 \%)$, que praticamente não variaram e, por último, 24 anos ou mais $(12,33 \%)$.

Quanto ao respeito ao semáforo, a faixa etária que apresentou maior porcentagem foi a faixa de estudantes entre 20 a 21 anos perfazendo 34,95\%, seguida pel as faixas entre 22 a 23 anos $(28,16 \%)$, pel os estudantes com 19 anos ou menos $(23,30 \%)$ e pelos estudantes com 24 anos ou mais $(13,59 \%)$ declarando transgressão ao semáforo.

Quanto às conversões ilegais, a faixa que apresentou maior freqüência para este comportamento foi a faixa de estudantes com 20 a 21 anos perfazendo $36,00 \%$ de declaração, seguida pelas faixas entre 22 a 23 anos $(29,50 \%)$, pel os de estudantes com 19 anos ou menos $(21,50 \%)$ e pelos estudantes com 24 anos ou mais $(13,00 \%)$.

Com relação às ultrapassagens proibidas, a faixa que apresentou maior freqüência foi a faixa de estudantes entre 20 a 21 anos perfazendo $34,27 \%$ de relatos, seguida pelas faixas entre 22 a 23 anos $(30,77 \%)$, pelos estudantes com 19 anos ou menos $(21,68 \%)$ e pelos estudantes com 24 anos ou mais $(13,29 \%)$

Com relação ao comportamento "falar ao celular enquanto dirige", a que apresentou maior freqüência foi a faixa entre 20 a 21 anos perfazendo $39,29 \%$, seguida pelas faixas de estudantes entre 22 a 23 anos $(25,45 \%)$, pelos estudantes com 19 anos ou menos $(23,21 \%)$ e pelos estudantes com 24 anos ou mais $(12,05 \%)$.

A ingestão de bebidas alcoólicas prévias à direção foi relatada por $41,91 \%$ na faixa entre 20 a 21 anos, seguida por $24,26 \%$ dos estudantes entre 22 a 23 anos, 20,59\% dos estudantes com 19 anos ou menos e $13,24 \%$ dos estudantes com 24 anos ou mais. 0 grupo dos jovens, especialmente, é mais vulnerável ao consumo de bebidas devido ao fácil acesso, incentivo da mídia e influência de familiares e amigos ${ }^{(26,27)}$.

0 uso de drogas foi relatado por $33,81 \%$ dos estudantes na faixa etária entre 20 a 21 anos, seguido por $28,10 \%$ dos estudantes entre 22 a 23 anos, $23,81 \%$ dos estudantes com 19 anos ou menos e $14,29 \%$ dos estudantes com 24 anos ou mais. Outra literatura discute que a utilização de drogas ilícitas ocorre principalmente entre adolescentes e jovens ${ }^{(28)}$, principalmente devido à experimentação precoce pela curiosidade de vivenciar novas experiências ${ }^{(29)}$.

Quanto a participação em "rachas", a faixa que apresentou maior freqüência foi entre 20 a 21 anos perfazendo $41,86 \%$, seguida pelas faixas entre 22 a 23 anos $(26,74 \%)$, pelos estudantes com 19 anos ou menos $(22,09 \%)$ e pelos estudantes com 24 anos ou mais $(9,30 \%)$.

Com relação à participação em brigas e discussões de trânsito foi encontrado maior freqüência deste comportamento para os estudantes entre 20 a 21 anos perfazendo $32,31 \%$, seguido pela faixa entre 22 a 23 anos $(29,23 \%)$, pel os estudantes com 19 anos ou menos $(21,54 \%)$ e pelos estudantes com 24 anos ou mais $(16,92 \%)$.

Os resultados obtidos demonstraram, de forma 
geral, que os comportamentos de risco no trânsito já estão presentes entre os estudantes com 19 anos ou menos, porém a maior freqüência destes comportamentos foi observada na faixa entre 20 a 21 anos. A pós esta idade estes comportamentos tendem a apresentar menores freqüências, o que poderia sugerir que com 0 amadurecimento emocional o jovem tenha mais consciência dos riscos da prática de comportamentos inadequados no trânsito.

$\mathrm{Na}$ França, em 1992, os acidentes de trânsito foram o principal problema de saúde entre jovens de 18 a 24 anos, tendo sido relatado por $69,30 \%$ dos jovens. $E$ ainda, que três de cada quatro mortes na faixa entre 15 a 19 anos são causadas por acidentes de trânsito ${ }^{(30)}$. N os Estados U nidos, os jovens também são o grupo com maior envolvimento em acidentes de trânsito fatais, onde $50 \%$ dos motoristas envolvidos estão na faixa entre 16 a 29 anos ${ }^{(31)}$. O utra literatura discute que os jovens teriam maior envolvimento em acidentes de trânsito devido à inexperiência e pouca adaptação ao trânsito. A lém disso, menciona que aspectos positivos e negativos da personalidade estão implícitos no ato de dirigir ${ }^{(16)}$.

Tabela 2 - Freqüências (absolutas (fi) e relativas (\%)) dos comportamentos de risco no trânsito de condutores segundo faixa etária, entre estudantes universitários de cursos na área da Saúde. Ponta G rossa, 2005

\begin{tabular}{|c|c|c|c|c|c|}
\hline \multicolumn{6}{|c|}{ Comportamentos de risco no trânsito de estudantes condutores segundo faixa etária } \\
\hline & $\begin{array}{c}19 \text { anos ou } \\
\text { menos } \\
(\mathrm{n}=125)\end{array}$ & $\begin{array}{c}20-21 \text { anos } \\
(n=166)\end{array}$ & $\begin{array}{c}22-23 \\
\text { anos } \\
(\mathrm{n}=112)\end{array}$ & $\begin{array}{l}24 \text { anos } \\
\text { ou mais } \\
(n=64)\end{array}$ & $\begin{array}{c}\text { Total } \\
(\mathrm{n}=461)\end{array}$ \\
\hline Comportamentos de risco & $\begin{array}{l}\mathrm{fi} \\
(\%)\end{array}$ & $\begin{array}{l}\text { fr } \\
(\%)\end{array}$ & $\begin{array}{l}\text { fi } \\
(\%)\end{array}$ & $\begin{array}{l}\text { fr } \\
(\%)\end{array}$ & $\begin{array}{c}\mathrm{fi} \\
(\%)\end{array}$ \\
\hline Nem sempre respeita o limite de velocidade & $\begin{array}{c}56 \\
(25,57)\end{array}$ & $\begin{array}{c}81 \\
(36,99)\end{array}$ & $\begin{array}{c}55 \\
(25,11)\end{array}$ & $\begin{array}{c}27 \\
(12,33)\end{array}$ & $\begin{array}{c}219 \\
(100,00)\end{array}$ \\
\hline Nem sempre respeita o semáforo & $\begin{array}{c}24 \\
(23,30)\end{array}$ & $\begin{array}{c}36 \\
(34,95)\end{array}$ & $\begin{array}{c}29 \\
(28,16)\end{array}$ & $\begin{array}{c}14 \\
(13,59)\end{array}$ & $\begin{array}{c}103 \\
(100,00)\end{array}$ \\
\hline Faz conversões ilegais & $\begin{array}{c}43 \\
(21,50)\end{array}$ & $\begin{array}{c}72 \\
(36,00)\end{array}$ & $\begin{array}{c}59 \\
(29,50)\end{array}$ & $\begin{array}{c}26 \\
(13,00)\end{array}$ & $\begin{array}{c}200 \\
(100,00)\end{array}$ \\
\hline Faz ultrapassagem proibida & $\begin{array}{c}31 \\
(21,68)\end{array}$ & $\begin{array}{c}49 \\
(34,27)\end{array}$ & $\begin{array}{c}44 \\
(30,77)\end{array}$ & $\begin{array}{c}19 \\
(13,29)\end{array}$ & $\begin{array}{c}143 \\
(100,00)\end{array}$ \\
\hline Fala ao celular enquanto dirige & $\begin{array}{c}52 \\
(23,21)\end{array}$ & $\begin{array}{c}88 \\
(39,29)\end{array}$ & $\begin{array}{c}57 \\
(25,45)\end{array}$ & $\begin{array}{c}27 \\
(12,05)\end{array}$ & $\begin{array}{c}224 \\
(100,00)\end{array}$ \\
\hline Ingestão de bebidas alcoólicas antes de dirigir & $\begin{array}{c}28 \\
(20,59)\end{array}$ & $\begin{array}{c}57 \\
(41,91)\end{array}$ & $\begin{array}{c}33 \\
(24,26)\end{array}$ & $\begin{array}{c}18 \\
(13,24)\end{array}$ & $\begin{array}{c}136 \\
(100,00)\end{array}$ \\
\hline Uso de drogas & $\begin{array}{c}50 \\
(23,81)\end{array}$ & $\begin{array}{c}71 \\
(33,81)\end{array}$ & $\begin{array}{c}59 \\
(28,10)\end{array}$ & $\begin{array}{c}30 \\
(14,29)\end{array}$ & $\begin{array}{c}210 \\
(100,00)\end{array}$ \\
\hline Participação em "rachas" & $\begin{array}{c}19 \\
(22,09)\end{array}$ & $\begin{array}{c}36 \\
(41,86)\end{array}$ & $\begin{array}{c}23 \\
(26,74)\end{array}$ & $\begin{array}{c}8 \\
(9,30)\end{array}$ & $\begin{array}{c}86 \\
(100,00)\end{array}$ \\
\hline Participação de brigas e discussões de trânsito & $\begin{array}{c}14 \\
(21,54)\end{array}$ & $\begin{array}{c}21 \\
(32,31)\end{array}$ & $\begin{array}{c}19 \\
(29,23)\end{array}$ & $\begin{array}{c}11 \\
(16,92)\end{array}$ & $\begin{array}{c}65 \\
(100,00)\end{array}$ \\
\hline
\end{tabular}

$\mathrm{Na}$ Tabela 3 estão apresentados os resultados relativos aos comportamentos de risco no trânsito de estudantes condutores conforme envolvimentos anteriores em acidentes de trânsito na condição de motoristas.

Com relação ao respeito do limite de velocidade segundo envolvimento anterior em acidentes de trânsito, observou-se presença de associação com valor estatístico al tamente significativo $(p=0,0047)$ onde $32,17 \%$ dos estudantes que se envolveram anteriormente e $17,14 \%$ que não se envolveram declararam desrespeito ao limite de velocidade.

Conforme sugerido em um estudo(4), a mídia pode acabar influenciando o comportamento dos jovens motoristas mais vulneráveis à pratica de comportamentos de risco, já que estão em fase de amadurecimento emocional e da personalidade. A lém disso, a inexperiência no trânsito e fatos inesperados na engenharia de tráfego, como pistas escorregadias, buracos, podem provocar acidentes de trânsito devido 
à al ta velocidade.

Quanto ao comportamento "nem sempre respeita o semáforo", encontrou-se alta freqüência para este comportamento tanto entre envolvidos como para não envolvidos $(59,13 \%$ e $40,00 \%$, respectivamente). Foi observado valor estatístico altamente significativo ( $p=0,0021)$, indicando prédisposição entre os estudantes que já se envolveram anteriormente em acidentes para transgredir ao semáforo.

Q uanto às conversões ilegais encontrou-se alta freqüência para este comportamento entre os estudantes que já se envolveram anteriormente em acidentes perfazendo $57,39 \%$ e $36,57 \%$ entre os estudantes que não tiveram envolvimento anterior. Observou-se associação entre as variáveis ( $p=0,0008$ ), indicando que os estudantes com envolvimento anterior em acidentes realizam conversões ilegais com maior freqüência.

Também foi observado valor altamente significativo $(p=0,0000)$ para a associação entre ultrapassagem proibida e envolvimento anterior em acidentes indicando pré-disposição para este comportamento entre os estudantes que já se envolveram anteriormente em acidentes de trânsito, perfazendo $48,70 \%$ e $23,43 \%$ entre os estudantes que não se envolveram. Freqüências inferiores foram encontrados em outro estudo, onde $29,70 \%$ dos acidentados e $19,90 \%$ dos estudantes que não se envolveram em acidentes relataram a prática de ultrapassagem proibida, tendo sido encontrado valor estatístico altamente significativo $(p=0,001)^{(12)}$. A ultrapassagem e mudança de pista são situações que exigem uma tomada de decisão em curto tempo, sendo que 0 envolvimento em acidentes estaria mais associado com a tomada dessa decisão de forma inadequada do que com a habilidade e experiência para controlar o carro $^{(32)}$.

Com relação ao comportamento "falar ao celular enquanto dirige", foi observado valor altamente significativo $(p=0,0062)$ indicando prédisposição para este comportamento entre os estudantes que já estiveram envolvidos anteriormente em acidentes, perfazendo $60,00 \%$ e $42,86 \%$ entre os que não se envolveram.

A associação entre ingestão de bebidas alcoólicas antes de dirigir e envolvimento anterior em acidentes de trânsito também revelou dependência entre as variáveis $(p=0,0000)$, onde $47,83 \%$ dos estudantes que já se envolveram anteriormente e
$21,71 \%$ dos estudantes que não se envolveram relataram ingestão de bebidas alcoólicas antes de dirigir. A diferença estatística encontrada revela que este tipo de comportamento de risco no trânsito está al tamente relacionado ao envolvimento em acidentes. F reqüências superiores foram encontradas em outro estudo, onde $56,50 \%$ dos acidentados e $31,40 \%$ dos não-acidentados relataram dirigir após beber, tendo sido encontrado valor estatístico significativo $(p=0,001)^{(12)}$. U ma pesquisa realizada anual mente nos Estados U nidos visando avaliar comportamentos de saúde entre os jovens discute que a ingestão de ál cool está presente em $50 \%$ dos acidentes de trânsito fatais (33). Outra literatura aponta que somente $9,7 \%$ das mulheres e $9,4 \%$ dos homens relataram nunca dirigir após beber(4).

A utilização de drogas também teve maior freqüência entre os estudantes que já se envolveram anteriormente em acidentes perfazendo $58,26 \%$ e $32,57 \%$ entre os estudantes que não tiveram envolvimento. O bservou-se valor estatístico al tamente significativo $(p=0,0000)$, indicando que a utilização de drogas está altamente ligada ao envolvimento em acidentes de trânsito. 0 abuso e dependência de drogas causam impactos sociais, econômicos e na saúde da população, além de elevar os índices de acidentes de trânsito, violência urbana e mortes repentinas e prematuras $^{(8,34)}$.

0 relato de participação em "rachas" também teve maior freqüência entre os estudantes que já se envolveram anteriormente em acidentes perfazendo $33,04 \%$ e $12,57 \%$ entre os estudantes que não se envolveram. Observou-se que a participação em "rachas" está altamente associada ao envolvimento em acidentes de trânsito $(p=0,0000)$. Outro estudo encontrou freqüências muito inferiores as do presente estudo, onde apenas 7,30\% dos acidentados e 3,40\% dos não-acidentados relataram participação em "rachas", tendo sido encontrado valor estatístico significativo $(p=0,001)^{(12)}$.

Foi observado valor estatístico altamente significativo $(p=0,0001)$ na associação entre envol vimento anterior em acidentes e participação em brigas e discussões de trânsito, onde $26,09 \%$ dos estudantes que já se envolveram anteriormente em acidentes e $8,57 \%$ dos estudantes que não se envolveram em acidentes declararam participação em brigas e discussões de trânsito. A diferença estatística encontrada revela que este tipo de comportamento é mais freqüente entre os estudantes 
que já se envolveram anteriormente em acidentes. Valores inferiores foram encontrados em outra literatura, onde $12,20 \%$ dos acidentados e $7,60 \%$ dos não acidentados declararam participação em brigas no trânsito, tendo sido encontrado valor estatístico significativo $(p=0,003)^{(12)}$.

Tabela 3 - Freqüências (absolutas (fi) e relativas (fr)), teste de associação e 0 dds R attio dos comportamentos de risco no trânsito de condutores segundo envolvimento anterior em acidentes de trânsito como motorista, entre estudantes universitários de cursos na área da Saúde. Ponta Grossa, 2005

Comportamentos de risco no trânsito de estudantes condutores segundo envolvimento anterior em acidentes de trânsito como motorista

\begin{tabular}{|c|c|c|c|c|c|c|}
\hline Comportamentos de risco & $\begin{array}{c}\text { Sim } \\
(\mathrm{n}=115) \\
\mathrm{fi} \\
(\mathrm{fr})\end{array}$ & $\begin{array}{c}\text { Não } \\
(\mathrm{n}=175) \\
\mathrm{fi} \\
(\mathrm{fr})\end{array}$ & $\mathrm{p}$ - value & OR & \multicolumn{2}{|c|}{ IC $(95 \%)$} \\
\hline Nem sempre respeita o limite de velocidade & $\begin{array}{c}37 \\
(32,17)\end{array}$ & $\begin{array}{c}30 \\
(17,14)\end{array}$ & 0,0047 & 2,2927 & 1,3167 & 3,9954 \\
\hline Nem sempre respeita o semáforo & $\begin{array}{c}68 \\
(59,13)\end{array}$ & $\begin{array}{c}70 \\
(40,00)\end{array}$ & 0,0021 & 2,1702 & 1,3439 & 3,5047 \\
\hline Faz conversões ilegais & $\begin{array}{c}66 \\
(57,39)\end{array}$ & $\begin{array}{c}64 \\
(36,57)\end{array}$ & 0,0008 & 2,3361 & 1,4443 & 3,7786 \\
\hline Faz ultrapassagem proibida & $\begin{array}{c}56 \\
(48,70)\end{array}$ & $\begin{array}{c}41 \\
(23,43)\end{array}$ & 0,0000 & 3,1021 & 1,8702 & 5,1455 \\
\hline Fala ao celular enquanto dirige & $\begin{array}{c}69 \\
(60,00)\end{array}$ & $\begin{array}{c}75 \\
(42,86)\end{array}$ & 0,0062 & 2,0000 & 1,2396 & 3,2268 \\
\hline Ingestão de bebidas alcoólicas antes de dirigir & $\begin{array}{c}55 \\
(47,83)\end{array}$ & $\begin{array}{c}38 \\
(21,71)\end{array}$ & 0,0000 & 3,3048 & 1,9789 & 5,5192 \\
\hline Uso de drogas & $\begin{array}{c}67 \\
(58,26)\end{array}$ & $\begin{array}{c}57 \\
(32,57)\end{array}$ & 0,0000 & 2,8896 & 1,7753 & 4,7034 \\
\hline Participação em "rachas" & $\begin{array}{c}38 \\
(33,04)\end{array}$ & $\begin{array}{c}22 \\
(12,57)\end{array}$ & 0,0000 & 3,4321 & 1,8983 & 6,2052 \\
\hline Participação de brigas e discussões de trânsito & $\begin{array}{c}30 \\
(26,09) \\
\end{array}$ & $\begin{array}{c}15 \\
(8,57)\end{array}$ & 0,0001 & 3,7647 & 1,9200 & 7,3816 \\
\hline
\end{tabular}

Para todos os comportamentos de risco avaliados foi verificada a dependência entre estes e 0 envolvimento anterior em acidentes de trânsito na condição de motoristas, através de val ores estatísticos altamente significativos. Tal resultado aponta para 0 fato de que transgredir leis ou adotar comportamentos agressivos e/ou abusivos pode aumentar o risco para envolvimento em acidentes de trânsito, sendo que em al guns destes comportamentos como partici pação em brigas e discussões de trânsito, participação em "rachas" e ingestão de bebidas alcoólicas antes de dirigir, as probabilidades de envolvimento são muito superiores quando comparadas àquelas envolvendo estudantes que afirmaram não adotar tais atitudes $(3,76 ; 3,43$ e 3,30 vezes, respectivamente). M esmo comportamentos considerados por muitos como irrelevantes como, por exemplo, falar ao celular enquanto dirige, já seria o suficiente para aumentar em 2 vezes a probabilidade de envolvimento em acidentes de trânsito, na condição de motorista.

Deforma complementar ao presente estudo, outra literatura encontrou maiores probabilidades para a ocorrência de acidentes entre estudantes que afirmaram receber multas, realizar subornos e dirigir no acostamento $(3,49 ; 3,09$ e 2,80 vezes, respectivamente) e probabilidades inferiores às encontradas no presente estudo quanto a participação em brigas e discussões no trânsito, participação em "rachas" e ingestão de bebidas alcoólicas (1,69; 2,23 e2,84 vezes, respectivamente) $)^{(12)}$.

Os resultados obtidos corroboram com outros estudos indicando jovens, principalmente do sexo masculino, como as vítimas mais freqüentes de acidentes de trânsito e pré-dispostos a assumir comportamentos inadequados no trânsito com maior freqüência do que o sexo feminino ${ }^{(2,6,12)}$. 


\section{CONSIDERAÇÕES FINAIS}

A pós a análise e interpretação dos resultados obtidos, concluiu-se que para os alunos dos Cursos da área da Saúde, da U niversidade Estadual de Ponta Grossa - UEPG, entrevistados no ano de 2005, a maior freqüência para todos os comportamentos indesejáveis no trânsito foi no sexo masculino. Quando realizada a associação entre os comportamentos de risco no trânsito e sexo encontrou-se pré-disposição no sexo masculino para a prática de quase todos os comportamentos em estudo.

Com relação à faixa etária, de maneira geral, os comportamentos de risco já estão presentes entre os estudantes com 19 anos ou menos. No entanto, a maior freqüência foi observada na faixa entre 20 a 21 anos, sendo que após esta idade as freqüências tendem a decrescer.

A associação entre os comportamentos de risco e envol vimento anterior em acidentes como motorista revelou dependência entre as variáveis, com resultados estatísticos al tamente significativos, havendo chances 2 a 3 vezes maiores de envolvimento em acidentes caso 0 estudante adote tais atitudes de risco no trânsito.

Conclui-se que os comportamentos inadequados no trânsito entre esses jovens estão presentes desde o início da aprendizagem como condutores, principalmente no sexo masculino. N esse sentido, sugere-se que a educação para o trânsito deva iniciar-se desde as séries escolares iniciais fazendose necessário a implementação da disciplina no seu currículo escolar. Assim, poderá contribuir na diminuição dos acidentes, uma vez que essas crianças crescerão conscientizadas sobre a boa educação no trânsitoo ${ }^{(35)}$.

\section{AGRADECIMENTOS}

Este trabalho contou com o apoio do Consel ho $\mathrm{Nacional}$ de Desenvolvimento Científico e Tecnológico (CN Pq) e da Universidade Estadual de Ponta Grossa, por intermédio de bolsas de iniciação científica.

\section{REFERÊNCIAS}

1. M ello-J orge M HP, Gawryszewski V P, L atorre M RDO. A cidentes e violência no Brasil. I - A nálise dos dados de mortalidade. Rev Saúde Públ 1997; 31 Suppl 4:5-25.
2. Carvalho RC, Costa M CO, Silva JJM, Rebouças MC. A cidentes de trânsito envolvendo adolescentes: 0 registro da situação de Feira de Santana, B ahia, 2001. Rev B aiana Saúde Públ 2005; 29(1):22-34.

3. Secretaria de E stado da Saúde do Paraná. Estatísticas de saúde - mortalidades - mortalidade por causas coeficiente de mortalidade por causas, Paraná, 2004 [acesso em 2006 Set 28]. Disponível em: www.saude.pr.gov.br

4. M arin L, Queiroz MS. A atualidade dos acidentes de trânsito na era da velocidade: U ma visão geral. Cad Saúde Púb 2000; 16:7-22.

5. Zuckerman $\mathrm{M}$. What lies beyond $\mathrm{E}$ and $\mathrm{N}$ ? Factor analyses of scales believed to measure basic dimensions of personality. J Pers Soc Psychol 1988; 54:96-107.

6. Andrade $S M$, Soares DA, Braga GP, M oreira JH, B otelho FM N . Comportamentos de risco para acidentes de trânsito: um inquérito entre estudantes de $M$ edicina na região Sul do B rasil. Rev A ssoc M éd B ras 2003; 49(4):439-44.

7. ShibataA, Fukuda K. Risk factors of fatal ity in motor vehicle traffic accidents. A ccid A nal Prev 1999; 31:593-7.

8. Carlini-Cotrim B, Gazal-Carvalho C, Gouveia N . Comportamento de saúde entre jovens estudantes das redes pública e privada da área metropol itana do Estado de São Paulo. Rev Saúde Públ 2000; 159(12):1180-8.

9. Alves MVQM, Costa M CO, Sobrinho CLN, Santos CAST, Gomes WA, Assis DR. U so de bebidas al coólicas entre adolescentes: perfil de experimentação, uso regular e fatores de risco. Feira de Santana- B ahia. Rev Baiana Saúde Públ 2005; 29(1):91-104.

10. Carlini EA, Carlini-Cotrim B, Silva-Filho A, B arbosa MTS. 20 Levantamento Nacional sobre 0 uso de psicotrópicos em estudantes de 1ํㅡ e $2^{\circ}$ graus - 1989. São Paulo: Centro Brasileiro de Informações sobre Drogas Psicotrópicas (CEBRID), 1989.

11. Centers of Disease Control and Prevention. Y outh risk behavior surveillance - U nited States, 1995. M M W R M orb M ortal W kly Rep 1996; 45(SS4):1-83.

12. M arín-L eón $L$, Vizzotto $M M$. Comportamentos no trânsito: um estudo epidemiológico com estudantes universitários. Cad Saúde Pub 2003; 19(2):515-23.

13. Estatíticas - A cidentes de trânsito - A nuário estatístico de acidentes de trânsito - 2002 - Tabela 1.4. Departamento Nacional de Trânsito - DENATRAN. Disponível em http://www.denatran.gov.br. (14/07/06).

14. Estatíticas - A cidentes de trânsito - A nuário estatístico de acidentes de trânsito - 2002 - Tabela 1.1.

Cogitare Enferm 2007 jan/mar; 12(1):20-9 
Departamento Nacional de Trânsito - DENATRAN. Disponível em http://www.denatran.gov.br (14/07/06).

15. Stocco C, Leite ML, Virgens Filho JS, Labiak VB. Caracterização epidemiológica dos acidentes de trânsito ocorridos dentro do perímetro urbano de Ponta G rossa, Paraná, 2002 - 2004. Rev Espaço Saúde; 7(2):8-16 [acesso em 2006 Jul 11]. Disponível em: http:// www.ccs.uel.br/espacoparasaude.

16. Chiarato DCA 0 parque temático do trânsito e a criação de estratégias para a criação do conhecimento [dissertação]. Florianópolis (SC): Programa de PósG raduação em Engenharia de Produção, U niversidade Federal de Santa Catarina; 2000.

17. A rnett JJ, Offer D, Fine M. Reckless driving in adolescence: "State" and "trait" factors. A cc A nal Prev 1993; 29:57-63.

18. Parker D, Reason JT, M anstead ASR, Stradling SG. Driving errors, driving violations and accident involvement. Ergonomics 1995; 38:1036-48.

19. Stocco C, Leite ML, Labiak VB, Virgens Filho JS. A cidentes de trânsito associados ao uso de bebidas al coólicas entre estudantes universitários. A nais do 80 Congresso Brasileiro de Medicina de Família e Comunidade e 20 Encontro Luso-B rasileiro de M edicina Geral, Familiar e Comunitária (SBM FC) 2006; (1):43.

20. A ndradeA G, Queiroz S, Villaboim RCM , César CLG, A lves M CGP, B assit AZ, et al. U so de álcool e drogas entre alunos de graduação da U niversidade de São Paulo (1996). Rev A BP-A PA L 1997; 19(2):53-9.

21. B oskovitz EP, Cruz ETN, Chiaravall oti-N eto F, M oraes MS, Paiva-N etto JV, Á vila LA, et al. U so de drogas em universitários em São J osé do Rio Preto, São Paulo. Rev Psiquiatr Clin 1995; 22:87-93.

22. Labiak VB, Leite ML, Stocco C, Virgens Filho JS. Características demográficas e sócio-econômicas de estudantes universitários associadas à participação em racha. A nais do 8 o Congresso B rasileiro de M edicina de Família e Comunidade e 2E Encontro L uso-Brasileiro de M edicina Geral, Familiar e Comunitária (SB M FC) 2006; (1):43-4.

23. D ouglas CR. Tratado de fisiologia aplicada à saúde. 5 . ed. São Paulo: Robe; 2002.

24. Silva P. Farmacologia. 6 a ed. Rio de J aneiro: Guanabara Koogan; 2002.

25. Thielen IP. Percepções de motoristas sobre excesso de velocidade no trânsito de Curitiba - Paraná, Brasil [tese]. Florianópolis (SC): Universidade Federal de Santa Catarina; 2002.
26. Baus J, Kupek $E$, Pires $M$. Prevalência e fatores de risco relacionados ao uso de drogas entre escolares. Rev Saúde Públ 2002; 36(1):40-6.

27. M arques A CPR, Cruz SC. 0 adolescente e 0 uso de drogas. Rev B ras Psiquitr 2000; 22 Suppl II:32-6.

28. $K$ andel $D B, Y$ amaguchi $K$. From beer to crack, developmental patterns of drug involvement. A m J Public Health 1993; 83(6):851-5.

29. Costa M CO, Souza RP. A val iação e cuidados primários da criança e do adolescente. Porto A legre: A rtes M édicas; 1998.

30. B audier $F$, J anvrin M P, D ressen $C$. L es jeunes français et leur santé. O pinions, attitudes et comportements. Promo Educ 1998; (1):29-35.

31. Williams AF, Carsten 0 . Driver age and crash involvement. A m J Public Health 1989; 79:326-7.

32. West R, French D, Kemp R, Elander J. Direct observation of driving, self reports of driver behaviour, and accident involvement. Ergonomics; 36:557-67.

33. Centers of Disease Control and Prevention. Quarterly table reporting alcohol involvement in fatal motorvehicle crashes. MMWR M orb M ortal W kly Rep; 42:215.

34. Lucas A CS, Parente RCP, Picanço NS, Conceição DA, Costa, K RC, M agal hães IRS, et al. U so de psicotrópicos entre universitários da área da saúde da U niversidade Federal do A mazonas, Brasil. Cad Saúde Públ 2006; 22(3):663-71.

35. B ova VBR, Wall M L. Educação em saúde no trânsito: uma contribuição da Enfermagem. Cogitare Enferm 2005; 10(1):60-5. 